\title{
Mecanismos Institucionais de Regulação Federal e seus Resultados nas Políticas de Educação e Saúde
}

\author{
Daniel Arias Vazquez \\ Universidade Federal de São Paulo (Unifesp), São Paulo, SP, Brasil. E-mail: \\ dvazquez@unifesp.br.
}

\begin{abstract}
T o Brasil, as reformas nas políticas de educação e saúde imple1 mentadas nos anos 1990 tinham como objetivo aperfeiçoar os desenhos dos programas e otimizar os recursos disponíveis por meio de novas formas de financiamento e de coordenação federativa. Estas reformas institucionais trouxeram novas formas de cooperação intergovernamental, mudanças nas regras de financiamento e novos incentivos colocados aos governos municipais para que eles assumissem e/ ou ampliassem a oferta das políticas reguladas, conforme as diretrizes definidas pelo governo federal.
\end{abstract}

A implementação das reformas exigiu a construção de estratégias diferenciadas, com o intuito de garantir a ampliação da eficácia das mesmas e a adesão dos governos subnacionais envolvidos. Dentre os mecanismos de regulação utilizados, destacam-se: a vinculação de receitas; a imposição de limites mínimos de gasto; a constituição de fundos específicos para o financiamento da política; as transferências condicionadas à oferta de programas; a definição de padrões nacionais para a execução local destes programas e a exigência de contrapartidas de recursos municipais. Para introduzir estas medidas, foram promovidas alterações na legislação (emendas constitucionais, leis complementares e normatizações editadas pelos ministérios), segundo o grau de institucionalidade necessário para garantir a adesão dos governos municipais e o alcance dos objetivos estabelecidos.

DADOS - Revista de Ciências Sociais, Rio de Janeiro, vol. 57, no 4, 2014, pp. 969 a 1005. 
As políticas que foram reguladas são justamente aquelas de caráter universal, cuja competência de oferta é compartilhada pelos três níveis de governo, a exemplo das áreas de educação e da saúde. As novas regras para o financiamento destas políticas impuseram condicionalidades para o recebimento de recursos federais vinculados à oferta de programas selecionados, a fim de que estes fossem executados localmente, mas sob diretrizes definidas centralmente.

Na educação básica, o financiamento e a oferta já eram predominantemente efetuados de forma descentralizada, por isso a disponibilização de receitas em proporção à oferta ocorreu por meio da formação de fundos compostos por subvinculações de receitas estaduais e municipais, criados por Emenda Constitucional, cujos recursos são redistribuídos dentro de cada Unidade da Federação (UF) em proporção ao número de matrículas nas respectivas redes de ensino.

Na saúde, ao contrário, a execução da política de atenção básica era descentralizada, mas o financiamento era feito em boa parte por transferências condicionadas da União (via Sistema Único de Saúde - SUS) e, por isso, a adequação entre a receita e a oferta de programas foi feita por meio dessas transferências, normatizadas por portarias ministeriais. Todavia, era necessária a complementação de recursos próprios municipais para cobrir os custos de oferta dos programas, viabilizados pela vinculação de receitas instituída por Emenda Constitucional.

Este artigo analisa, em primeiro lugar, os aspectos institucionais e federativos das reformas nas políticas de educação e saúde, destacando os mecanismos utilizados e as alterações necessárias no ordenamento jurídico, para verificar, em seguida, se as novas regras e incentivos introduzidos implicaram aumento da oferta da política, do gasto per capita e uma distribuição mais equânime dos recursos disponíveis às áreas em questão, a partir da avaliação dos resultados obtidos pelo Fundo de Manutenção e Desenvolvimento do Ensino Fundamental e Valorização do Magistério (Fundef) no financiamento da educação e pelo Piso de Atenção Básica (PAB) no financiamento da política de saúde ${ }^{1}$.

A unidade de análise será os municípios brasileiros. Esta opção se justifica pela crescente importância da relação direta entre União e municípios, sendo a esfera local a responsável prioritária pela oferta das políticas aqui estudadas. Além disso, em função das dificuldades de coordenar esforços de mais de 5.500 governos municipais, a análise no plano municipal permitirá testar com maior força a capacidade dos 
instrumentos de regulação federal. Já o recorte temporal tem como ponto de referência o momento de implantação de cada mecanismo de regulação em análise, abrangendo todo o seu período de funcionamento (1998 a 2006) e também alguns anos anteriores à vigência do mesmo, conforme a disponibilidade dos dados, cujas fontes são a base do Finbra (Finanças do Brasil), da Secretaria do Tesouro Nacional, e as estatísticas disponibilizadas pelos Ministérios da Educação e da Saúde.

Os resultados deste estudo mostram que foi possível direcionar mais recursos para as políticas reguladas, ampliar a oferta municipal e, ao mesmo tempo, reduzir as desigualdades horizontais em relação aos valores per capita aplicados pelos municípios nas áreas de educação e saúde. Os recursos dos fundos específicos (Fundef/Fundeb) e as transferências condicionadas do SUS (PAB fixo e variável) passaram a ser distribuídos por critérios próprios das políticas, que independem da capacidade contributiva de cada município, sendo condicionados apenas à oferta das políticas, cujo crescimento foi bastante forte. Por sua vez, a vinculação de recursos serviu para definir um patamar mínimo de gasto e para garantir as contrapartidas municipais, já que os repasses federais tornaram-se cada vez mais insuficientes para cobrir os custos de oferta destas políticas, uma vez que valores que norteiam as transferências da União não foram corrigidos adequadamente.

\section{REFORMAS NAS POLÍTICAS DE EDUCAÇÃO E SAÚDE: ASPECTOS INSTITUCIONAIS E FEDERATIVOS}

AConstituição de 1988 promoveu significativa descentralização fiscal, seja pela ampliação da base tributária dos governos subnacionais (em especial, dos estados), seja pelo aumento das transferências aos estados e, principalmente, aos municípios. Porém, o texto constitucional não definiu claramente as responsabilidades pela oferta das políticas sociais entre as esferas de governo, já que a provisão ficou sob competência partilhada entre todos os níveis de governo na maioria das políticas sociais setoriais (Lobo, 1995).

Assim, qualquer ente federativo estava constitucionalmente autorizado a implementar programas nas áreas de saúde, educação, assistência social, habitação e saneamento. Simetricamente, nenhum ente federativo estava constitucionalmente obrigado a implementar programas nestas áreas, pois as competências partilhadas, por si só, não garantem cooperação ou uma ação coordenada entre os três níveis de governo 
(Arretche, 2004). De acordo com Castro et al. (2009), esta definição exigia uma regulamentação posterior por meio de legislação ordinária e, enquanto isso não ocorreu, houve desequilíbrios e controvérsias que perduraram nos anos posteriores à promulgação da Constituição.

Segundo Arretche (2004), o princípio de atuação descentralizada não era autoexecutável, ou seja, era necessário introduzir novas regras para estimular a descentralização e induzir os municípios a assumirem e ampliarem a oferta descentralizada das políticas sociais, pois diferentemente da pressão pela descentralização de recursos, não havia pressão de baixo para cima para a descentralização dos encargos.

Se, logo após a promulgação da Constituição de 1988, a federação brasileira era caracterizada pela ausência de definição clara de competências entre as esferas de governo (Serra e Afonso, 1999) e de coordenação federativa do processo de descentralização (Affonso, 1995; Arretche, 1999,2004), as reformas implantadas na segunda metade dos anos 1990 - além de impulsionar o processo de descentralização de encargos, especialmente na área social - introduziram mecanismos de regulação federal que disciplinam a alocação dos recursos e a oferta de determinada política.

O desafio colocado à agenda de reformas introduzida na segunda metade dos anos 1990 era o estabelecimento de mecanismos de regulação federal, sem a alteração no regime político, visando garantir a efetiva descentralização das políticas sociais, uma coordenação federativa no financiamento e um padrão nacional de atuação, capaz de reduzir as desigualdades nos recursos disponíveis e nas condições de oferta das políticas sociais ${ }^{2}$. Com esta finalidade, esta regulação federal introduziu diversos mecanismos institucionais que produziram incentivos para que os governos locais adotassem comportamentos esperados, definidos pelo governo central, tais como: 1) o direcionamento de recursos descentralizados para políticas definidas como prioritárias e 2) a implementação e gestão das políticas, sob competência local, a fim de garantir um padrão nacional e reduzir as desigualdades horizontais.

De acordo com Melo, as transformações provocadas pelas reformas de segunda geração no Brasil só foram possíveis "pela reestruturação do padrão de relações intergovernamentais [...], a partir dos incentivos e capacidades institucionais" (2005:846). Em contraposição, Arretche (2009) afirma que não houve ruptura em relação às relações intergovernamentais definidas pela Constituição, pois em 1988 já estava defi- 
nido um modelo de Estado federativo que combinava ampla autoridade jurisdicional à União, com a descentralização fiscal.

Independentemente, se as reformas institucionais representaram transformação radical no federalismo definido em 1988 (Melo, 2005) ou se consolidam um poder regulatório já conferido à União pela Constituição Federal (Arretche, 2009), houve de fato uma mudança prática nas relações intergovernamentais após 1995, quando a autonomia decisória dos governos subnacionais passou a ser afetada por regras e incentivos definidos pelo governo federal, que antes destas reformas não existiam. Dessa forma, o desafio aqui é analisar como estas mudanças foram colocadas em prática.

A implementação das reformas exigiu a construção de estratégias diferenciadas, com o intuito de garantir a ampliação da eficácia das mesmas e a adesão dos governos subnacionais envolvidos. Para cada tipo de política foram consideradas as especificidades e a participação de cada esfera de governo na oferta e no financiamento das políticas em reforma, ou seja, o legado da política influenciou na formulação das reformas, pois só assim seria possível gerar os incentivos corretos para a adesão dos governos locais (Vazquez, 2012).

O primeiro passo, portanto, foi definir qual deve ser o grau de mudança necessário no aparato legal para a implantação dos novos mecanismos de regulação. Por exemplo, para a criação dos fundos de manutenção e desenvolvimento da educação (Fundef/Fundeb) e para estabelecer a vinculação de receitas para o financiamento da saúde foram necessárias Emendas Constitucionais (EC), sendo este o instrumento jurídico-institucional necessário para alterar o padrão de financiamento das políticas descentralizadas quando estas são custeadas basicamente por recursos já disponíveis aos governos subnacionais.

Quando as políticas são executadas localmente e com parte significativa do financiamento proveniente do orçamento federal - como na atenção básica à saúde -é possível definir regras a partir de normas ministeriais (portarias, manuais, regras para transferências), já que os recursos são repassados caso os critérios para oferta sejam respeitados e, com isso, pode-se obter a cooperação dos municípios e estabelecer um padrão nacional de oferta dos programas.

O segundo passo é definir os instrumentos utilizados para a coordenação federativa e para a indução dos governos municipais ao comporta- 
mento esperado, os quais também devem ser adequados ao tipo e às características da política em análise. Dentre a gama destes mecanismos, destacam-se três tipos que estão presentes nas reformas implementadas nas políticas de educação e da saúde: vinculação de receitas; fundos específicos; e transferências condicionadas, os quais estão brevemente descritos a seguir.

\section{Vinculação de Receitas}

Aárea da educação já contava com recursos vinculados das três esferas de governo antes da Constituição, por meio da Emenda Calmon, de 1983. Posteriormente, a área da saúde passou a contar com a vinculação de recursos estaduais e municipais por meio da Emenda Constitucional nํㅡㄹ 29, com o intuito de ampliar a participação destas esferas no financiamento do setor e de cativar os recursos necessários às contrapartidas municipais no financiamento dos programas de atenção básica à saúde.

Este tipo de instrumento de regulação pode ser considerado aquele com maior capacidade de intervenção na decisão de gasto dos governos. Segundo Mendes, a vinculação, de um lado, "induz os governos subnacionais a aumentarem seus investimentos em um tipo de serviço público considerado prioridade nacional; por outro lado, ela diminui os graus de liberdade que o gestor municipal tem para decidir sobre a alocação de recursos" (2003:11). Consequentemente, as decisões de gasto dos governos locais seriam menos explicadas pela iniciativa autônoma e mais por regulamentações legais, que vinculam recursos, por exemplo, de $25 \%$ de suas receitas em educação e de $15 \%$ em saúde. Mais que isto, para além dos percentuais de gasto, a Constituição e legislações específicas definem mais detalhadamente modalidades previstas de gasto, tais como: $15 \%$ no ensino fundamental; percentual com salários de professores (no mínimo, 60\%); serviços de atenção básica à saúde; campanhas de saúde preventiva; distribuição de remédios (Arretche, 2004).

Diante disso, os efeitos esperados da vinculação de receitas como mecanismo de regulação federal são a ampliação do gasto municipal nas áreas sociais reguladas por meio da imposição de um patamar mínimo. Isto, por sua vez, implica a vinculação entre receita e gasto, fazendo com que as desigualdades horizontais no gasto sejam expressas pelas diferenças existentes nos recursos disponíveis para cada município. 


\section{Fundos Específicos}

Compostos por receitas das três esferas de governo, cujos recursos são destinados ao financiamento de programas sociais executados localmente, a partir da disponibilização de receitas em proporção à oferta destes programas pelos estados e, principalmente, pelos municípios, a partir de critérios próprios da política (oferta), promovendo redistribuição de recursos entre estas esferas.

No geral, estes fundos são mecanismos de coordenação federativa sobre a alocação dos recursos descentralizados, através da formação de fundos específicos destinados ao financiamento das políticas definidas pelo governo federal (Almeida, 2005; Abrucio, 2005). Segundo Oliveira (2003), estes mecanismos de coordenação federativa (por meio de cooperação financeira intergovernamental) representam avanços nos processos de descentralização, estabelecendo vínculo entre encargos e capacidade fiscal, aperfeiçoando as relações federativas pós-1988. O autor afirma que os recursos cativos estimulam a descentralização e aumentam as responsabilidades dos governos subnacionais quanto ao financiamento e gestão das políticas sociais.

O Fundef/Fundeb são casos exemplares. Ambos são formados por uma subvinculação de recursos fiscais dos estados e municípios, com os repasses aos respectivos governos condicionados à oferta do ensino e norteados por um valor único aluno/ano para cada etapa da educação básica. Com isso, espera-se que as desigualdades horizontais diminuam sensivelmente no âmbito de cada estado e que os recursos adicionais diminuam a resistência dos governos municipais em assumir a oferta desta política.

\section{Transferências Condicionadas}

Estas transferências ganharam importância no Brasil a partir da segunda metade dos anos 1990, revelando-se um importante instrumento de coordenação federativa. Segundo Prado (2007), este tipo de transferência intergovernamental reflete um esforço para o alcance de objetivos nacionais em áreas que são definidas constitucionalmente como encargos tipicamente subnacionais ou de competência compartilhada. Além de preencher a brecha vertical (vertical gap), são exigidas contrapartidas para que os repasses possam ser realizados, os quais são orientados por regras gerais associadas à oferta da política, conferindo um caráter automático e contínuo aos repasses, caso as exigências este- 
jam sendo cumpridas. Dessa forma, as condicionalidades impostas para os repasses afetam as decisões alocativas e restringem a autonomia orçamentária dos municípios.

Esta estratégia é utilizada principalmente no financiamento das áreas englobadas pela seguridade social, nas quais os recursos federais respondem por parte significativa do financiamento das políticas, como é o caso da atenção básica à saúde. Em suma, as transferências condicionadas no Brasil possibilitam o repasse de recursos para os municípios, fornecendo incentivos para que estes executem programas específicos, sob diretrizes definidas centralmente. Por outro lado, os repasses possuem critérios redistributivos (população, por exemplo) e/ou próprios de cada programa financiado (como no caso do Programa Saúde da Família) e, com isso, espera-se que estas transferências também colaborem com a redução das desigualdades horizontais no financiamento da saúde.

Após identificar os mecanismos institucionais de coordenação federativa e de regulação sobre a gestão descentralizada das políticas de educação e da saúde, o próximo passo é avaliar os desenhos, as relações intergovernamentais e os resultados obtidos pelas reformas nas políticas sociais. Optou-se pelo foco nas políticas e não nos instrumentos de regulação pelo fato de que diferentes instrumentos estão contidos em uma mesma política. Por exemplo, a educação conta com a vinculação de receitas e com fundos específicos, já a saúde também possui a vinculação, mas o fundo é composto por recursos da União e repassado aos municípios via transferências condicionadas, conforme disposto no Quadro 1. Com esta análise, pretende-se destacar o conjunto de regras e incentivos que visam estabelecer um padrão de atuação dos municípios na execução local destas políticas.

É importante notar que não se trata de uma única estratégia de regulação aplicada em diferentes áreas de atuação governamental. Ao contrário, segundo Vazquez (2012:96), cada instrumento de regulação introduzido "considerou as especificidades e o legado das políticas, nas questões relativas às competências pelo financiamento e pela execução das mesmas, às necessidades de expansão da oferta, à produção de estímulos à descentralização e à introdução de mecanismos de redistribuição dos recursos e de compatibilização entre receita e oferta". Daí a importância de avaliação da eficácia dos instrumentos de coordenação federativa e dos resultados obtidos em cada área, pois além de poder 


\section{Quadro 1}

Regulação Federal/Coordenação Federativa, por Área de Atuação

\begin{tabular}{|c|c|c|c|}
\hline $\begin{array}{l}\text { Área de } \\
\text { Atuação }\end{array}$ & $\begin{array}{c}\text { Reformas } \\
\text { Institucionais }\end{array}$ & $\begin{array}{c}\text { Ordenamento } \\
\text { Jurídico-Institucional }\end{array}$ & Casos \\
\hline $\begin{array}{l}\text { Educação } \\
\text { Básica }\end{array}$ & $\begin{array}{l}\text { Vinculação de receitas das } \\
\text { três esferas de governo; } \\
\text { Fundos multigovernamentais } \\
\text { com recursos dos estados e } \\
\text { dos municípios; } \\
\text { Repasses proporcionais à } \\
\text { oferta. }\end{array}$ & $\begin{array}{l}\text { Emendas } \\
\text { Constitucionais } n^{\circ} \\
\text { 14/1996 e n } 53 / 2006 ; \\
\text { Lei } n^{\circ} 9.424 / 1996 \text { e } \\
\text { Lei } n^{\circ} 11.494 / 2007 \text {. }\end{array}$ & $\begin{array}{l}\text { Fundef/ } \\
\text { Fundeb }\end{array}$ \\
\hline $\begin{array}{c}\text { Atenção } \\
\text { Básica à } \\
\text { Saúde }\end{array}$ & $\begin{array}{l}\text { Transferências federais } \\
\text { condicionadas para } \\
\text { programas específicos; } \\
\text { Vinculação de receitas dos } \\
\text { governos estaduais e } \\
\text { municipais. }\end{array}$ & $\begin{array}{l}\text { Normas Operacionais } \\
\text { Básicas - NOB/SUS; } \\
\text { Cartilhas de } \\
\text { orientações técnicas } \\
\text { dos ministérios; } \\
\text { Emenda } \\
\text { Constitucional no } 29 \\
\text { (vinculação saúde). }\end{array}$ & $\begin{array}{l}\text { PAB Fixo e } \\
\text { Programa } \\
\text { Saúde da } \\
\text { Família } \\
\text { (PSF) }\end{array}$ \\
\hline
\end{tabular}

Fonte: Elaboração do autor com base na revisão bibliográfica e análise da legislação.

subsidiar eventuais correções destes mecanismos, estas experiências poderão servir de base para a construção de novas regulações para políticas até então não reguladas, considerando suas especificidades.

\section{A REGULAÇÃO FEDERAL NA POLÍTICA DE EDUCAÇÃO}

O financiamento de políticas públicas mediante a constituição de um fundo se realiza pela destinação de receitas específicas que, por lei, vinculam-se à realização de determinados objetivos. Estes fundos desempenham papel relevante no financiamento de políticas públicas de competência compartilhada entre diferentes níveis de governo, cujos recursos são obtidos pela vinculação de receitas destas esferas e, por outro lado, os repasses oriundos do fundo serão efetuados de acordo com a oferta dos programas em cada estado/município.

No Brasil, fundos desta natureza foram criados por iniciativa do governo federal para o financiamento da educação, por meio de Emendas Constitucionais. Inicialmente, foi criado o Fundef, pela Emenda Constitucional no 14/1996 (EC 14), cuja cobertura abrangia apenas a oferta do ensino fundamental regular. Após oito anos de funcionamento (1998-2006), o Fundef foi extinto e um novo fundo foi instituído pela 
Emenda Constitucional no 53/2006 (EC 53), o qual mobilizou mais recursos e ampliou a cobertura deste mecanismo de financiamento para todas as etapas e modalidades da educação básica, mantendo praticamente o mesmo desenho e as principais regras do primeiro fundo. Este novo fundo é denominado Fundo de Manutenção e Desenvolvimento da Educação Básica e de Valorização dos Profissionais do Magistério (Fundeb), cuja vigência será de 14 anos.

Após a instituição dos fundos, alterou-se a estrutura de incentivos para que os governos municipais assumissem a oferta dos níveis de ensino definidos, constitucionalmente, como de competência municipal. O principal mecanismo utilizado foi modificar as regras de financiamento - primeiramente, do ensino fundamental e, posteriormente, de toda a educação básica - ao garantir recursos adicionais transferidos pelo fundo para cada aluno matriculado nas redes municipais e estaduais de ensino.

Este estudo pretende avaliar, primeiramente, a redistribuição dos recursos vinculados à educação entre governos estaduais e municipais, promovida pelos fundos criados no âmbito de cada estado, com o intuito de disponibilizar recursos em proporção à oferta de ensino em cada esfera de governo. Em seguida, serão avaliados os resultados dos incentivos colocados por estas reformas no financiamento da educação, verificando se houve ampliação da oferta de ensino pelos municípios e redução das desigualdades horizontais no plano nacional.

Como o foco é a avaliação dos resultados, optou-se por centrar a análise no período de vigência do Fundef (1998-2006). Este fundo foi formado por 15\% dos seguintes impostos e transferências: Imposto sobre Circulação de Mercadorias e Serviços (ICMS); Fundo de Participação dos Estados e Municípios (FPE/FPM); Imposto sobre Produtos Industrializados, proporcional às exportações (IPI-Exp); ressarcimento pela desoneração das exportações, de que trata a Lei Complementar no 87/1996 (Lei Kandir). Adicionalmente, foi prevista uma participação da União no financiamento do Fundef, com o intuito de complementar os fundos estaduais em que a vinculação de receitas não fosse suficiente para garantir a aplicação de um valor mínimo aluno/ano definido nacionalmente ${ }^{3}$.

A introdução de um critério educacional para os repasses das receitas vinculadas promoveu uma redistribuição de recursos entre os governos estaduais e municipais, com o objetivo de disponibilizar mais ver- 
bas às instâncias responsáveis pela oferta da política, compatibilizando recursos disponíveis aos encargos de cada nível de governo, sendo respeitadas as competências definidas constitucionalmente. Este novo mecanismo de financiamento, instituído no âmbito de cada unidade federada (UF), permitiu o repasse de um valor único por aluno/ano, independente da rede de ensino, municipal ou estadual, em que este está matriculado e da capacidade contributiva destas esferas. O valor repassado é dado pela razão entre o total das receitas vinculadas ao fundo e o total de matrículas nas redes estadual e municipal em cada UF.

A introdução deste fundo pode ser interpretada como uma nova regulação federal que alterou as regras, especialmente, da redistribuição dos recursos, ao vincular os repasses à oferta da política e, com isso, produz novos incentivos às escolhas dos governantes das esferas subnacionais de governo. Segundo Gomes, o Fundef é exemplo "das propriedades de uma instituição na perspectiva do novo institucionalismo [...], já que o objetivo desta perspectiva analítica é identificar como cada instituição influencia o comportamento e o resultado da forma mais universalista possível" (2008:15). Para esta autora, a introdução do Fundef representa uma característica estruturante, uma vez que este mecanismo de financiamento pode ser interpretado como "uma norma institucional que altera os cálculos dos governos subnacionais", com a redistribuição dos recursos em proporção à oferta, em que o governo municipal e estadual que "tem alunos é premiado com receitas orçamentárias e, por outro lado, quem não tem alunos (ou atende poucos), é punido com perda de receitas" (ibidem:17).

Por último, os aspectos federativos que envolvem o funcionamento de um fundo composto por recursos são: 1) a criação de uma subvinculação de receitas ao ensino fundamental (60\% das receitas já vinculadas aos gastos em MDE - Manutenção e Desenvolvimento do Ensino deveriam ser aplicadas naquele nível de ensino), criando, assim, um novo constrangimento às decisões alocativas dos governos locais; 2) a limitação da autonomia local sobre a aplicação dos recursos do fundo, já que as definições do que compõe ou não as despesas em MDE também foram especificadas por legislação federal; 3) a relação de "perde/ganha" em relação ao fundo, uma vez que a redistribuição de recursos provocada pelo funcionamento do Fundef gerou saldos positivos para 
alguns municípios, resultantes de uma contribuição ao fundo menor do que os repasses recebidos do mesmo, enquanto a situação inversa foi observada em outros municípios (ou governos estaduais) e; 4) a introdução de novos estímulos à ampliação da oferta, pois a única forma de um município reverter um eventual saldo negativo seria ampliando a oferta de matrículas na sua rede de ensino.

O primeiro resultado esperado é a expansão da oferta como um todo, tendo em vista que os repasses adicionais do fundo cobririam, ao menos em parte, o custo do aumento da oferta, isto é, o custo de oportunidade das novas matrículas ficou menor, principalmente diante do elevado custo social de ter um aluno fora da escola. Portanto, espera-se uma expansão das matrículas totais no ensino fundamental, visando a universalização deste nível de ensino. De acordo com os dados de Vazquez (2003), notou-se uma forte expansão nos dois primeiros anos do Fundef, mais especialmente nos estados das regiões Norte e Nordeste, onde se concentrava o maior número de crianças fora da escola. Após a incorporação deste contingente sem acesso à educação, que ocorreu nos dois primeiros anos do Fundef, teve início uma trajetória decrescente das matrículas no ensino fundamental, graças a fatores demográficos. Conforme mostra o Gráfico 1, o número total de matrículas nas redes públicas - estadual e municipal - de ensino fundamental caiu 2,4\% entre 1997 e 2006.

Outro fenômeno deflagrado após a introdução do Fundef, demonstrado no Gráfico 1, foi a descentralização do ensino fundamental, seja pela expansão da rede própria municipal, seja pela municipalização das escolas e matrículas das redes municipais. Se, de um lado, as matrículas totais tiveram decréscimo no período 1997-2006, de outro, as redes municipais cresceram $44,5 \%$, enquanto as redes estaduais de ensino fundamental apresentaram forte queda $(-34,5 \%)$ no número de matrículas no período analisado. Obviamente, houve uma forte transferência de oferta do ensino fundamental dos estados para os municípios. $\mathrm{Na}$ análise comparativa entre as trajetórias das matrículas do ensino fundamental no período de funcionamento do Fundef por esfera de governo e com os dados desagregados por UF, fica evidente o forte movimento de descentralização durante a vigência do Fundef no plano nacional. Mesmo nos estados nos quais não ocorreu queda significativa das matrículas estaduais, houve uma forte expansão das redes municipais. 


\section{Gráfico 1}

Variação Total das Matrículas de Ensino Fundamental, segundo Rede de Ensino

(1997-2006)

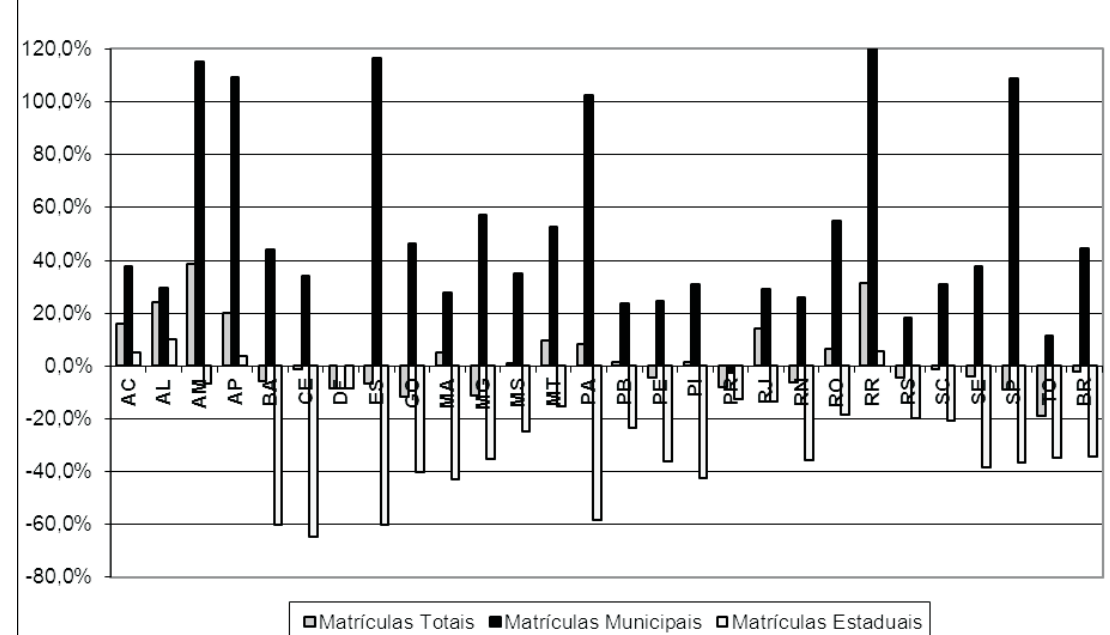

Fonte: Ministério da Educação (MEC)/Instituto Nacional de Estudos e Pesquisas Educacionais Anísio Teixeira (Inep).

Embora a criação do fundo não tenha estabelecido nenhuma obrigatoriedade de descentralização da oferta aos municípios - a competência pela oferta continuou compartilhada entre os governos estadual e municipal - de fato, houve uma expansão das redes municipais em detrimento das estaduais, sendo que este movimento é mais forte nos anos iniciais do fundo. Ainda que se admita que o Fundef não seja a única variável que explica este processo de municipalização (Gomes, 2009), é fácil sustentar que sem ele este processo não aconteceria nas mesmas proporções, ou seja, se a mudança no financiamento da educação não foi o único motivo para desencadear este processo, sem dúvida o fundo foi um pré-requisito importante, na medida em que garante recursos adicionais para as novas matrículas.

Esta descentralização implica crescimento dos repasses do fundo em direção aos municípios e em saldos positivos destas instâncias em relação ao Fundef. A evolução dos recursos do fundo transferidos para os governos estaduais e municipais durante a vigência do Fundef pode ser observada no Gráfico 2 a seguir. 


\section{Gráfico 2}

Crescimento Real das Transferências do Fundef para os Governos Estaduais e Municipais, por UF

(1998-2006)

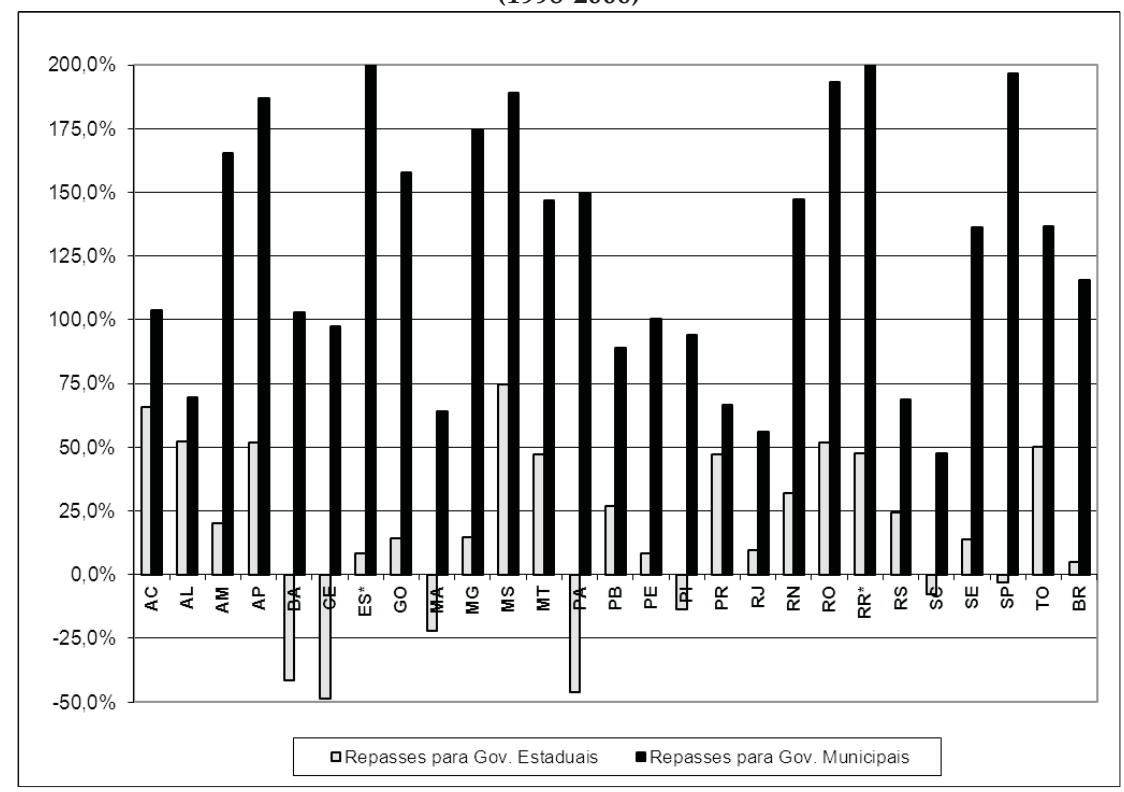

Fonte: Elaboração do autor com base nos dados do MEC. Valores deflacionados pelo Índice Nacional de Preços ao Consumidor (INPC)/Instituto Brasileiro de Geografia e Estatística (IBGE).

Obs.: Para melhorar a visualização do gráfico, optou-se por limitar a escala do eixo X e, por isso, o crescimento real dos repasses aos municípios do Espírito Santo e de Roraima - que foram, respectivamente, de 353,6\% e 846,3\% - não aparecem no gráfico. Esta análise não faz sentido no Distrito Federal (não existe o nível municipal).

O Gráfico 2 mostra que a queda percentual na participação dos governos estaduais nos repasses do fundo não significa, necessariamente, que houve redução no volume de recursos em valores reais. Ao contrário, são poucos os casos em que houve redução real das transferências do Fundef aos governos estaduais (apenas sete casos), em todos eles esta queda foi inferior à redução na oferta de matrículas nestas redes estaduais. Mesmo com a queda no número de matrículas estaduais, as transferências do Fundef a estas esferas de governo cresceram, em valores reais, pouco mais de 5\% entre 1998 e 2006. Por outro lado, os aumentos reais no volume de recursos do fundo destinados aos governos municipais também superaram a expansão destas redes: o aumento real foi da ordem de $115 \%$ frente ao crescimento de $45 \%$ das matrículas municipais, conforme os Gráficos 1 e 2. 
O segundo resultado esperado é a redução das desigualdades horizontais no plano nacional. Para verificar a contribuição do Fundef para o equilíbrio federativo, realizou-se um exercício a partir dos dados sobre finanças municipais da base Finbra, disponibilizados pela Secretaria do Tesouro Nacional, a fim de calcular as receitas disponíveis à manutenção e desenvolvimento do ensino (MDE) para cada município compostas pelas receitas transferidas do Fundef, mais $10 \%$ das transferências que compõem o fundo e mais $25 \%$ das receitas municipais próprias, que não são vinculadas ao Fundef, mas que devem ser aplicadas em educação - e, em seguida, este montante foi dividido pelo total de matrículas em cada rede municipal pública. Com isso, foi possível obter uma simulação de um valor médio aplicado por aluno / ano em cada município ${ }^{4}$.

Em contraposição, foi realizada outra simulação, caso o Fundef não existisse. Neste caso, foram retiradas do cálculo as transferências obtidas do fundo e foi agregada a contribuição efetuada por cada município ao fundo, isto é, $15 \%$ das transferências vinculadas ao Fundef, mantendo-se o mesmo denominador. $\mathrm{O}$ valor obtido representa uma simulação do valor médio per capita aplicado por cada município, caso o Fundef não existisse.

Após a construção destas duas variáveis para cada município, optou-se por mensurar a desigualdade entre os casos pela utilização do coeficiente de Gini. A adaptação foi fácil, pois os municípios podem ser considerados uma população que apresenta uma distribuição de gasto per capita em educação. Os resultados para o período de 2000 a $2006^{5}$ estão apresentados no Gráfico 3 a seguir.

Nota-se que a desigualdade no valor por aluno / ano disponível para o investimento em educação (receitas vinculadas à MDE) seria muito maior caso o Fundef não vigorasse, o que pode ser explicado pela redistribuição de recursos promovida pelo fundo no âmbito de cada estado. No plano intraestadual, cada matrícula no ensino fundamental corresponde a um repasse único do fundo, sendo estes recursos complementados pela parcela de receitas vinculadas à educação e que não foram incluídas no Fundef, mas que devem ser obrigatoriamente aplicadas no ensino fundamental e também na educação infantil, ambas etapas de competência municipal.

Outra constatação importante é que a desigualdade entre os municípios em relação a estes recursos diminuiu significativamente durante o 
Gráfico 3

Coeficiente de Gini da Receita Vinculada à Educação - MDE, com e sem os Efeitos do Fundef, por Aluno/Ano da Rede Municipal

(2000-2006)

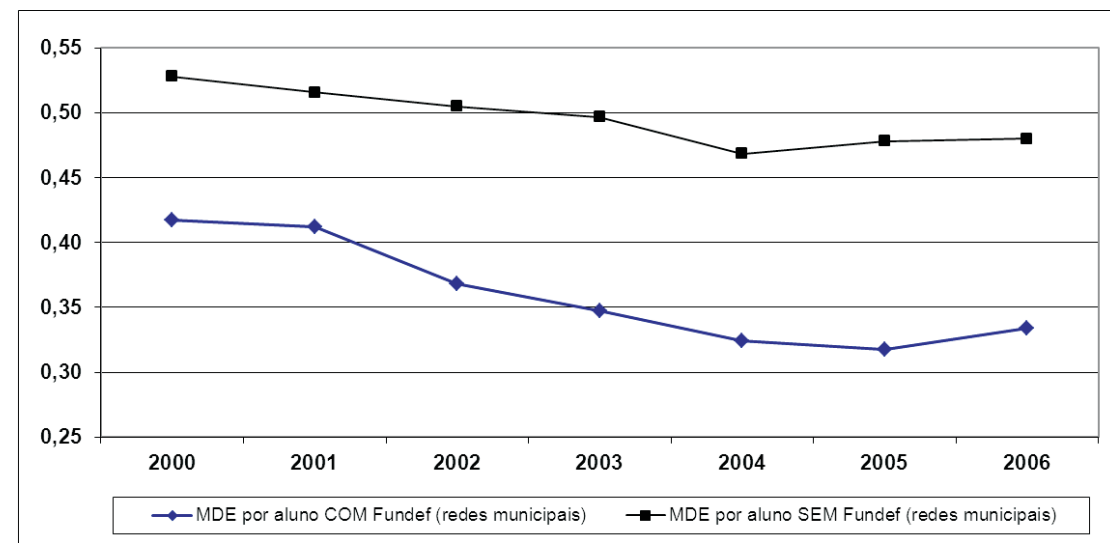

Fonte: Secretaria do Tesouro Nacional (STN) / Finbra (Receita-MDE) e Inep/Censo Escolar (matrículas).

período analisado, mesmo se o Fundef não estivesse em vigor. Logo, esta queda não pode ser atribuída somente à política de correção das desigualdades interestaduais (via complementação da União) prevista pelo fundo, mas, sim, ao comportamento das receitas que o compõem. Alias, é importante ressalvar que os avanços observados na redução das desigualdades horizontais poderiam ter sido maiores, caso a participação da União no financiamento do fundo não tivesse sido tão baixo.

Segundo Vazquez (2007), o governo federal descumpriu o art. 6o da Lei no 9.424/96, que apontava a fórmula que deveria ser observada para a definição do valor mínimo nacional. De acordo com o texto legal, o valor mínimo deveria ser igual ao valor médio nacional, o que implicaria uma equalização a partir desta média. $\mathrm{O}$ autor também afirma que os valores mínimos aluno/ano, definidos durante a vigência do Fundef, além de não obedecerem à fórmula estabelecida no art. 6으 da Lei no 9.424, também sofreram reajustes inferiores ao crescimento das receitas do fundo, com exceção do ano de 2004. Isto provocou uma defasagem deste patamar mínimo que "nos três primeiros anos de vigência do fundo, representava pouco mais de $75 \%$ da média nacional, [...] no último ano do programa, o valor mínimo estipulado pelo governo federal correspondia a 63\% do valor legal" (ibidem:255). 
Obviamente que se o valor anual mínimo fosse determinado de acordo com a fórmula estabelecida no art. 6 o da Lei no 9.424 ou reajustado em proporção superior ao crescimento das receitas do Fundef, isto implicaria um maior volume de recursos federais destinados à complementação da União, pois aumentaria os repasses para os fundos estaduais que receberam efetivamente a complementação, além de aumentar o número de estados que fariam jus a estes recursos, contribuindo para reduzir ainda mais as desigualdades horizontais.

Com a redução da participação da União no financiamento do Fundef, devido à falta de correção adequada dos valores que norteiam as transferências de recursos federais, são necessários esforços maiores dos municípios para fazer frente aos custos da oferta do ensino fundamental, após a forte expansão das matrículas nas redes municipais, especialmente nas unidades federativas com menor capacidade tributária e que, por isso, deveriam ter seus fundos complementados com recursos federais. Mesmo com esta limitação, deve-se ressaltar aqui os importantes avanços obtidos com as mudanças no financiamento do ensino fundamental promovidas pelo Fundef. Os resultados deste estudo dão evidências claras de que esta regulação resultou em uma ampliação dos esforços dos governos municipais na oferta e no financiamento da educação. Comprovou-se empiricamente que:

1) O acesso ao ensino fundamental foi praticamente universalizado, pois houve forte crescimento das matrículas já nos anos iniciais de funcionamento do fundo, especialmente nas UFs em que a taxa de cobertura era menor.

2) Houve forte municipalização deste nível de ensino, já que as resistências dos municípios em assumir a oferta foram retiradas ao garantir recursos adicionais em proporção ao número de matrículas nas redes municipais.

3) A redistribuição de recursos promovida pelo Fundef reduz as desigualdades horizontais, uma vez que o valor aluno/ano repassado pelo fundo é igual dentro de cada UF, independente da capacidade contributiva de cada esfera de governo.

4) Houve redução da participação da União no financiamento do fundo, em função do baixo valor mínimo nacional definido pelo governo federal, o que exigiu mais esforço dos governos subnacionais para assumir os custos de oferta do ensino fundamental e, ao mesmo tempo, impediu uma queda maior nas desigualdades horizontais. 


\section{A REGULAÇÃO FEDERAL NA POLÍTICA DE SAÚDE}

Nesta seção, serão analisados os resultados da regulação federal sobre a política de saúde. Pretende-se demonstrar aqui que esta nova regulação - que combinou a vinculação de receitas dos governos subnacionais com a nova lógica dos repasses do SUS (condicionados à oferta e que exigem contrapartidas municipais) - permitiu uma ampliação da oferta e uma redução das desigualdades no plano nacional. Os incentivos são, de um lado, a obrigatoriedade de gasto para a ampliação da parcela de recursos próprios destinada à saúde e, de outro, os repasses federais só estariam disponíveis caso os municípios assumissem a oferta de programas de saúde.

Para avaliar os efeitos das regulações federais implantadas, pretende-se, primeiramente, verificar se houve aumento dos recursos aplicados pelos municípios no financiamento da saúde, por meio de receita própria e das transferências condicionadas do SUS. Em seguida, serão analisados os resultados da regulação federal em relação à ampliação do gasto total em saúde e, também, a contribuição que foi dada no que tange à redução das desigualdades horizontais no financiamento da saúde.

A ampliação da participação dos governos estaduais e municipais no financiamento da saúde era o objetivo da vinculação de recursos estabelecida pela Emenda Constitucional no 29 (EC 29), aprovada em setembro de 2000. Com a implantação gradual, obrigou os municípios e estados a aplicarem, inicialmente, $7 \%$ das receitas de impostos e transferências em saúde no primeiro ano, até alcançarem 12\% e 15\% das receitas estaduais e municipais, respectivamente, no ano de 2004. Apesar de a regulamentação desta emenda ter ocorrido apenas em $2012^{6}$, acredita-se que esta medida tenha contribuído para ampliar os recursos dos estados e, principalmente, dos municípios na área da saúde.

Segundo Vianna (2005), a vinculação representa um instrumento importante para fazer com que as esferas menores de governo cumpram sua parte no financiamento das políticas sociais. Para verificar se isto ocorreu, optou-se por analisar a evolução dos valores aplicados em saúde em cada município, segundo a origem (recursos municipais disponíveis ou transferências do SUS). O período analisado abrange os anos de 1999 a 2006, pois apesar de disponível, o exercício de 1998 não segue a mesma metodologia dos anos posteriores e não pôde ser incluído na série histórica analisada. O Gráfico 4 mostra a evolução do gasto 
Gráfico 4

Crescimento Real dos Valores per capita Aplicados pelos Municípios, segundo a Fonte de Recursos

(1999-2006)

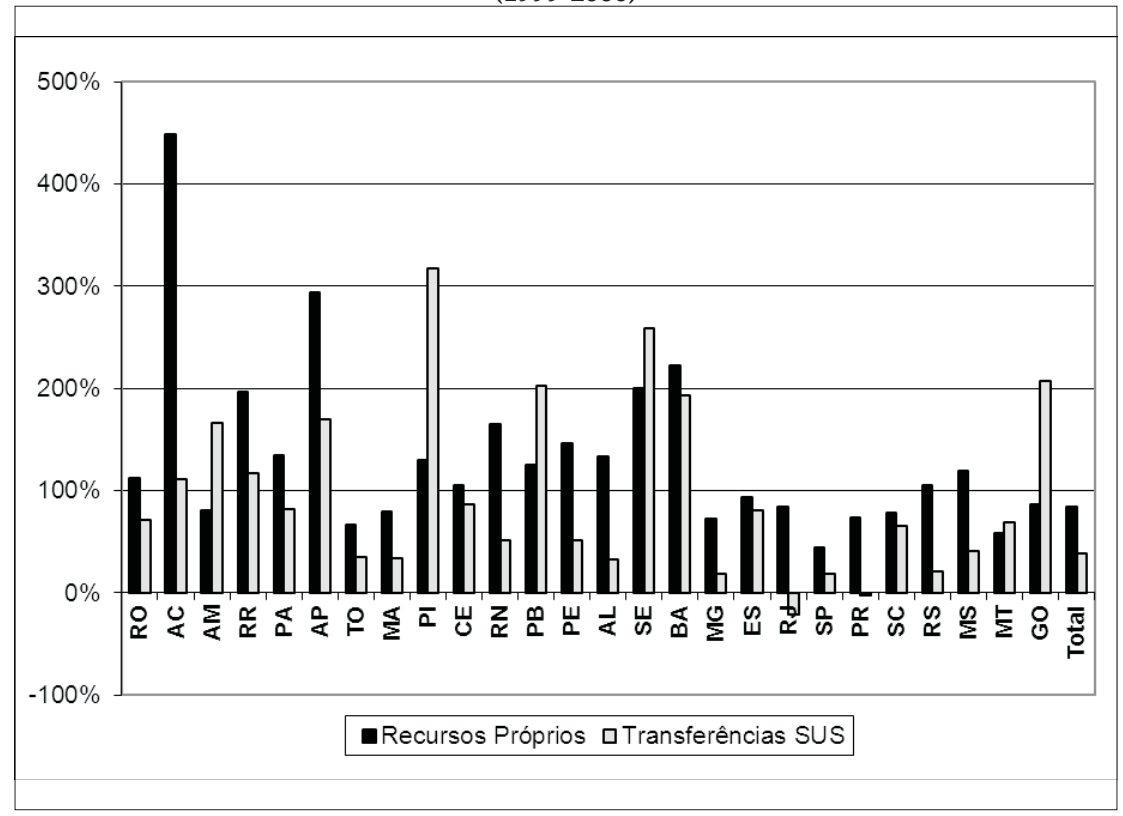

Fonte: SIOPS/DATASUS. Valores deflacionados pelo Índice Nacional de Preços ao Consumidor Amplo (IPCA)/IBGE.

municipal em saúde, por meio da aplicação de recursos próprios e das transferências recebidas via SUS.

O resultado agregado nacional revela que os gastos financiados com recursos dos orçamentos municipais cresceram $85 \%$, já a expansão do gasto financiado pelas transferências do SUS foi de $38 \%$, ou seja, menos da metade do aumento observado nos gastos próprios municipais. Os desempenhos por UF precisariam ser analisados caso a caso, pois foram constatadas diferenças significativas entre elas, sendo que houve cinco casos em que as transferências cresceram mais que os gastos com recursos próprios, enquanto nos demais casos e no agregado nacional se observou o contrário. Uma possível justificativa para estas diferenças está no ponto de partida da série analisada. Por exemplo, o gasto com recursos transferidos dos municípios piauienses em 1999 representou menos de um terço do valor gasto no ano seguinte; o mesmo pode ser dito em relação à expansão do gasto próprio dos municípios do Acre, pois também partiu de um patamar muito baixo.

DADOS - Revista de Ciências Sociais, Rio de Janeiro, vol. 57, nº 4, 2014 
Em suma, o aumento do gasto municipal em saúde como um todo deve ser atribuído à forte expansão dos recursos próprios destinados à saúde, superior à expansão das transferências do SUS, devido aos efeitos da vinculação dos recursos imposta pela EC 29. De acordo com Vazquez, "os governos municipais foram aqueles que mais aumentaram seus gastos em saúde com recursos próprios [...], com isso, a participação do gasto municipal no financiamento da saúde cresceu de 22\%, em 2000, para 28\%, em 2006" (2012:231). Todavia, a regulação federal sobre o financiamento da saúde não se limitou à vinculação estabelecida pela EC 29. Foram definidas regras para os repasses do SUS e quanto à forma como os municípios efetuam a gestão descentralizada da política da saúde, cujas diretrizes foram colocadas por meio das Normas Operacionais Básicas (NOBs). Estas normas estabeleceram a atenção básica como foco da política e definiram uma série de processos automáticos de descentralização de recursos condicionados à oferta de programas considerados estratégicos pelo Ministério da Saúde.

Para Cajueiro (2004), havia uma incerteza quanto aos mecanismos de financiamento e acerca da capacidade do Ministério da Saúde de cumprir com os repasses previstos, o que tornava arriscado assumir responsabilidades que implicassem despesas adicionais significativas. Apesar do propósito de promover a municipalização, ainda faltavam regras claras e incentivos mais fortes - sobretudo no lado financeiro para que os municípios assumissem a gestão da política da saúde.

Visando eliminar estes obstáculos, a NOB 01/96 estabeleceu uma nova forma de financiamento que prevê a criação de fundos exclusivos para o financiamento da saúde nos três níveis de governo, cujas transferências de recursos ocorrem entre estes fundos (do Fundo Nacional de Saúde para os fundos estaduais e municipais de saúde), de acordo com a adesão de cada município a uma das duas formas previstas de gestão municipal: a plena de atenção básica e a plena do sistema de saúde.

A partir desta nova regulamentação, concluída apenas em 1998, os repasses para a atenção básica passaram a ser efetuados ex-ante, condicionados à oferta ex-post de ações de saúde por parte dos municípios. Para tanto, foi instituído o PAB, o qual foi subdividido da seguinte maneira: 1) o PAB fixo, que é calculado com base em um valor per capita, ou seja, os recursos são proporcionais à população e devem ser utilizados para o atendimento das especialidades de atenção básica; e 2) o PAB variável, com incentivos financeiros especiais para programas priori- 
tários definidos pelo governo federal, tais como: os programas de Saúde da Família (PSF) e de Agentes Comunitários de Saúde (PACS); Programa de Gestão do Atendimento Básico; Programa de Farmácia Básica; Combate a grandes endemias e os Programas de Saúde da Mulher e da Criança, sendo que estas receitas extras dependem da adesão dos municípios aos programas já em curso, conforme desenho definido pelo Ministério da Saúde (Souza, 2003; Melamed e Costa, 2003).

De acordo com Arretche, utilizou-se "um conjunto sucessivo de portarias ministeriais, a partir das quais a burocracia do Ministério da Saúde foi progressivamente organizando uma estrutura de incentivos destinada a obter a adesão dos municípios aos objetivos da reforma" (2002:452), as quais foram sendo moldadas, segundo Viana e Machado, por meio da elaboração de "novas modalidades de transferência de recursos (per capita e por programas específicos) e instrumentos para priorizar a descentralização da atenção básica e incentivar a oferta de programas definidos como prioritários pelo Ministério da Saúde" (2009:812).

Acredita-se que as transferências condicionadas forneceram incentivos para que os municípios aderissem ao SUS e, mais especificamente, assumissem a oferta de programas de atenção básica definidos como prioritários pelo Ministério da Saúde, já que uma boa parte do financiamento da saúde é feita por repasses federais, mediante a adesão dos municípios à gestão da atenção básica pelo SUS (para os repasses do PAB fixo) e aos programas definidos como prioritários pelo Ministério da Saúde (no caso, do PAB variável). A seguir, pretende-se verificar o resultado desta regulação quanto à capacidade de estimular os municípios a assumirem a oferta das ações de atenção básica da saúde no período 1998-2006. Como as transferências do PAB variável dão conta de vários programas definidos como prioritários pelo governo federal, optou-se pela análise do Programa Saúde da Família.

Os Gráficos 5 e 6 fazem o cruzamento entre o crescimento real dos repasses do SUS (PAB fixo e PAB variável - PSF) e a evolução da oferta do atendimento de saúde prestado pelos municípios, que será mensurada a partir de três indicadores: a) a produção ambulatorial de atendimento básico; b) o número de visitas realizadas pelas equipes de saúde da família (PSF); de agentes comunitários de saúde (PACS); e c) o número de famílias acompanhadas por estes programas (PSF/PACS). 


\section{Gráfico 5}

Taxa Anual de Crescimento dos Repasses do PAB Fixo e da Produção Ambulatorial de Atendimento Básico (prestador municipal)

(1999-2006)

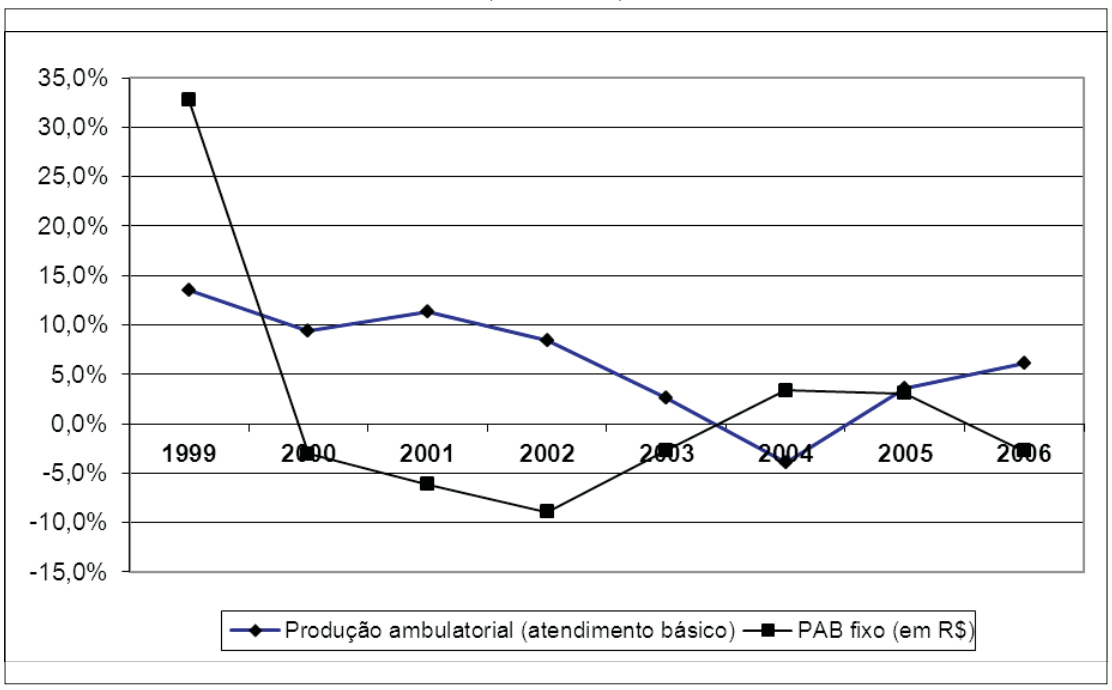

Fonte: SIOPS e SIASUS/DATASUS. Valores deflacionados pelo IPCA/IBGE.

\section{Gráfico 6}

Taxa Anual de Crescimento dos Repasses do PAB Variável - PSF, do Número de Famílias Atendidas pelo Programa e do Número de Visitas Efetuadas (1999-2006)

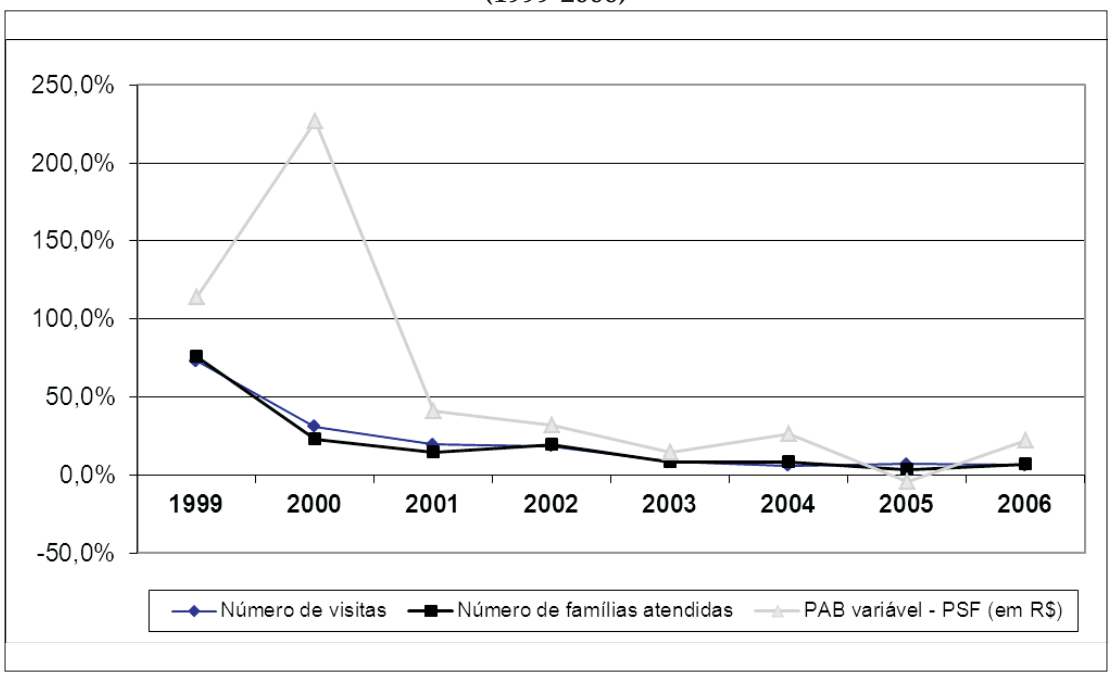

Fonte: SIOPS e SIASUS/DATASUS. Valores deflacionados pelo IPCA/IBGE. 
Nos dois casos, as transferências cresceram nos anos iniciais por conta da ampliação da oferta da atenção básica de saúde e do PSF pelos municípios, pois a perspectiva de uma fonte adicional e estável de recursos para a oferta da saúde forneceu incentivos necessários para a adesão dos municípios. Nos primeiros anos de implantação dos programas, quando a adesão dos municípios precisava ser efetivada, as transferências de recursos federais cresceram em proporção superior à produção municipal de serviços de saúde. A justificativa se deve ao esforço necessário para conquistar a "cooperação" dos municípios, o que exige repasses iniciais mais generosos, visando estimular a adesão dos governos municipais mediante as transferências condicionadas à oferta dos programas, nos moldes definidos pelo governo federal.

Nos anos seguintes, observou-se que o crescimento real dos repasses ficou abaixo (no caso do PAB fixo) ou apenas acompanhou (no caso do PAB variável - PSF) a expansão da oferta de ações da saúde. A justificativa está na ausência de correção adequada dos valores per capita que norteiam as transferências do $\mathrm{PAB}$, consequentemente, os recursos federais não aumentaram no mesmo ritmo. De acordo com os dados de Solla et al., o valor per capita do PAB fixo ficou estagnado até 2003, quando "o Ministério da Saúde estabeleceu uma estratégia de correção progressiva, aumentando o PAB fixo, com seu valor mínimo saindo de R\$ 10,00 para $\mathrm{R} \$ 13,00^{\prime \prime}$ (2007:497).

De acordo com Vazquez (2012), o valor per capita do PAB fixo foi ficando defasado em relação ao valor inicialmente praticado em 1998, pois se este tivesse sido corrigido segundo o IPCA, em vez de R $\$ 17,00$, o valor do PAB fixo deveria ser de quase $\mathrm{R} \$ 20,50 \mathrm{em} 2009$, para manter o poder de compra de 1998. O valor do incentivo para as equipes do PSF também sofreu correção inferior à inflação, já que deveria ser superior a $R \$ 9$ mil mensais em 2009, enquanto o valor vigente era de $R \$ 6$ mil (modalidade 2).

O motivo para a ausência de correção dos valores do PAB se deve ao "impacto financeiro desta decisão, pois o aumento destes valores implicaria aumento dos recursos federais doSUS para municípios prestadores dos serviços de atenção básica" (Vazquez, 2012:245). Logo, se os custos de oferta do programa cresceram nestes anos - o que certamente aconteceu -, os valores repassados pelo governo federal se tornaram cada vez mais insuficientes para cobrir a totalidade dos custos do pro- 
grama, passando a exigir uma contrapartida maior dos recursos próprios municipais.

Em suma, quando o governo federal busca a adesão dos governos municipais, os valores repassados cobrem uma parcela significativa dos custos, o que dá incentivos para que os municípios implantem os programas selecionados. Os repasses federais tendem a crescer bastante nos anos iniciais, pois refletem a adesão em massa dos municípios. Porém, nos anos seguintes, após a implantação dos programas na grande maioria dos municípios, os valores repassados pelo governo federal não sofreram as devidas correções, reduzindo a participação destas transferências no financiamento dos programas de atenção básica. Com isso, são exigidas contrapartidas municipais maiores, pois os custos de oferta dos programas crescem, bem como a pressão social para a continuidade e expansão da cobertura destes programas.

Ainda em relação à expansão de oferta descentralizada, a Tabela 1 fornece a quantidade de procedimentos ambulatoriais de atenção básica à saúde prestados pela rede municipal em 1998 e 2006, bem como o número de visitas efetuadas e de famílias atendidas pelo PSF/PACS, sendo que todas estas informações estão desagregadas por UF. A unidade de análise será os municípios agrupados por estado, para os quais também será apurada a variação percentual dos indicadores selecionados no período 1998-2006.

Em primeiro lugar, deve-se destacar que a produção ambulatorial municipal cresceu $62,3 \%$, o número de visitas saltou $324,5 \%$ e a quantidade de famílias atendidas pelo PSF aumentou em $282 \%$, considerando a oferta descentralizada total. Estes números evidenciam a forte expansão das ações de atenção básica de saúde prestadas pelos municípios. Para explicar as diferenças entre as UFs, é importante notar que onde ocorreu crescimento em proporção bastante superior à média nacional os programas de atenção básica à saúde tinham baixa cobertura ou não eram prestados pelos municípios. Portanto, uma variação percentual muito alta pode ser explicada por um patamar inicial bastante baixo. Prova disso são os números observados nos estados do Acre, Amazonas e Roraima em relação à produção ambulatorial, cuja variação percentual superou $350 \%$ e que, sem dúvida, está relacionada ao baixo patamar inicial da quantidade de procedimentos prestados pelos municípios destes estados. Em seguida, aparecem cinco UFs nas quais a produção ambulatorial municipal cresceu entre 100\% e 200\%: Pará, 
Mecanismos Institucionais de Regulação Federal

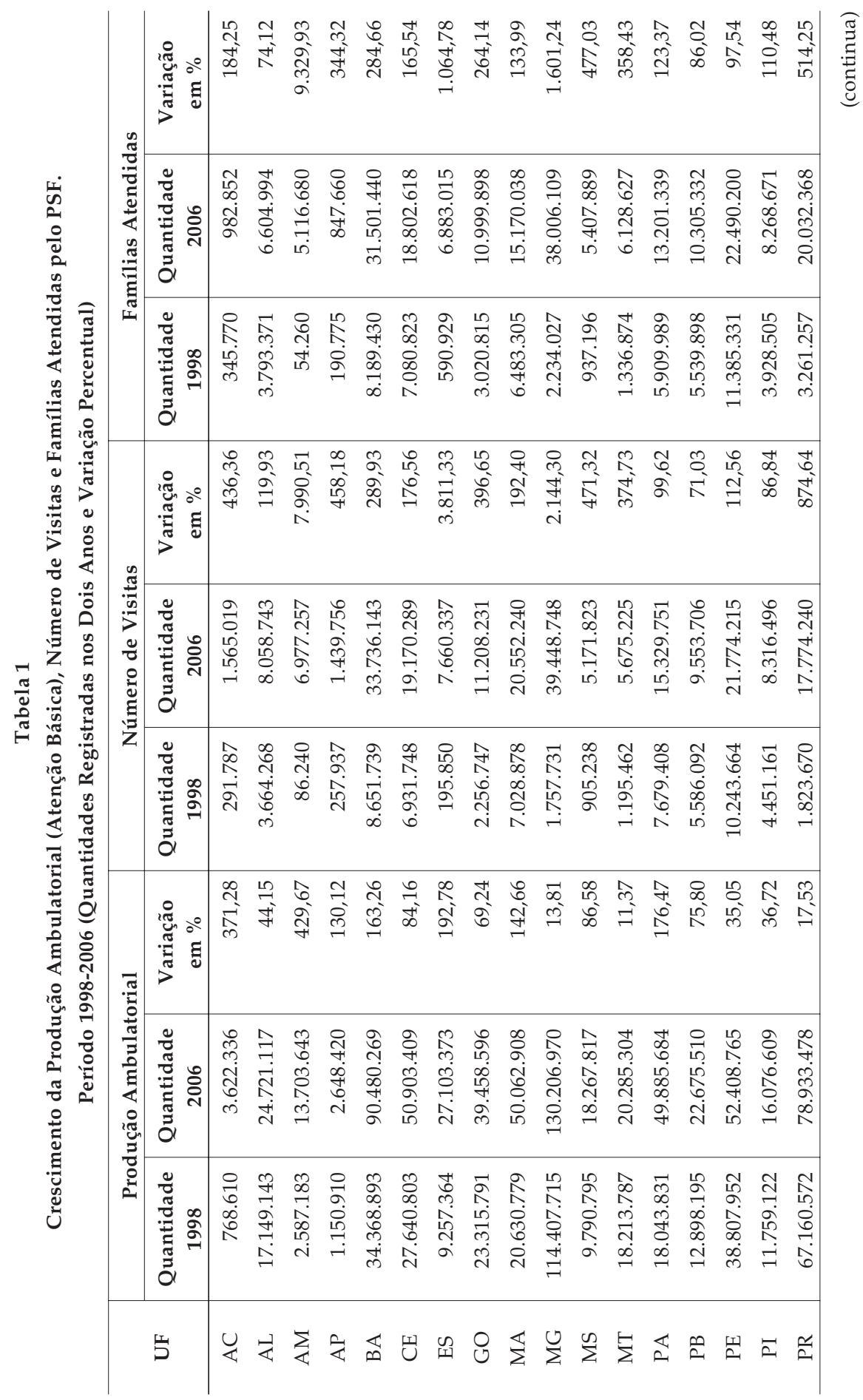

DADOS - Revista de Ciências Sociais, Rio de Janeiro, vol. 57, nํㅡ, 2014 


\section{Daniel Arias Vazquez}

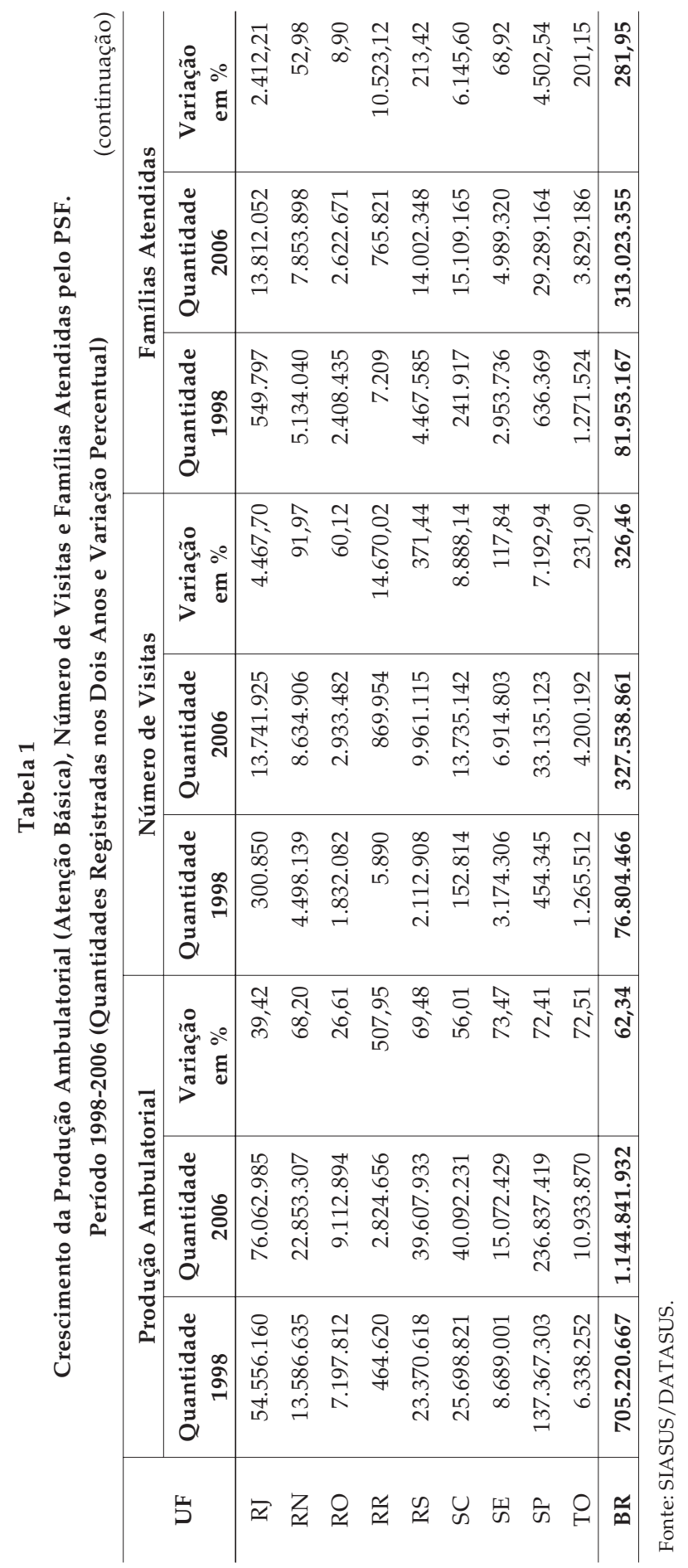


Amapá, Maranhão, Bahia e Espírito Santo. Em relação aos programas PSF e PACS, a Tabela 1 também demonstra um aumento percentual do número de famílias cobertas e da quantidade de visitas efetuadas no período 1998 a 2006. Deve-se destacar que houve crescimento da cobertura, com mais famílias acompanhadas pelo programa, e também aumento do número de visitas por família, já que a quantidade de visitas cresceu em proporção superior à expansão das famílias atendidas.

Os maiores saltos ocorreram nos municípios do Amazonas, de Roraima, de São Paulo e de Santa Catarina. A justificativa para os elevados percentuais é a mesma: o patamar inicial era bastante baixo, o que explica o forte crescimento na participação relativa dos seus municípios no total de famílias atendidas pelo PSF/PACS em 2006, em comparação com o ano inicial (1998). Por outro lado, todos os estados da região Nordeste (exceto a Bahia) tiveram crescimento abaixo da média nacional, o que também ocorreu para o conjunto dos municípios de Rondônia, Pará e Acre, onde a cobertura inicial era maior.

Em suma, a forte expansão das ações de atenção básica em todo o território nacional demonstra o sucesso da estratégia de regulação federal sobre o financiamento e a gestão descentralizada da política de saúde em estimular a ampliação da oferta da atenção básica pelos municípios, sendo que esta expansão foi financiada, principalmente, pelo crescimento dos gastos municipais, conforme já demonstrado anteriormente. Resta saber se as novas regras introduzidas, especialmente em relação ao financiamento da política, também foram capazes de reduzir as desigualdades horizontais no plano nacional. O Gráfico 7 mostra o coeficiente de Gini calculado para cada exercício do período ${ }^{7}$.

Nota-se que a justificativa para a queda na desigualdade em relação ao gasto per capita aplicado por cada município está na redução das diferenças em relação ao gasto próprio, como também em função de uma distribuição mais equânime das transferências do SUS.

No primeiro caso, a queda da desigualdade está relacionada com a regulação federal sobre as decisões de gasto municipal, resultante da introdução da vinculação das receitas municipais ao financiamento da saúde. Nota-se que a queda do coeficiente de Gini do gasto próprio em saúde sofreu forte inflexão para baixo nos anos de implantação da vinculação (especialmente, até 2003), pois com a ampliação gradual do percentual mínimo destinado à saúde, elevou-se o patamar de gasto daqueles municípios que aplicavam um percentual inferior. Ao mes- 


\section{Gráfico 7}

Coeficiente de Gini do Gasto em Saúde Total e Desagregado por

Origem dos Recursos

(2000-2006)

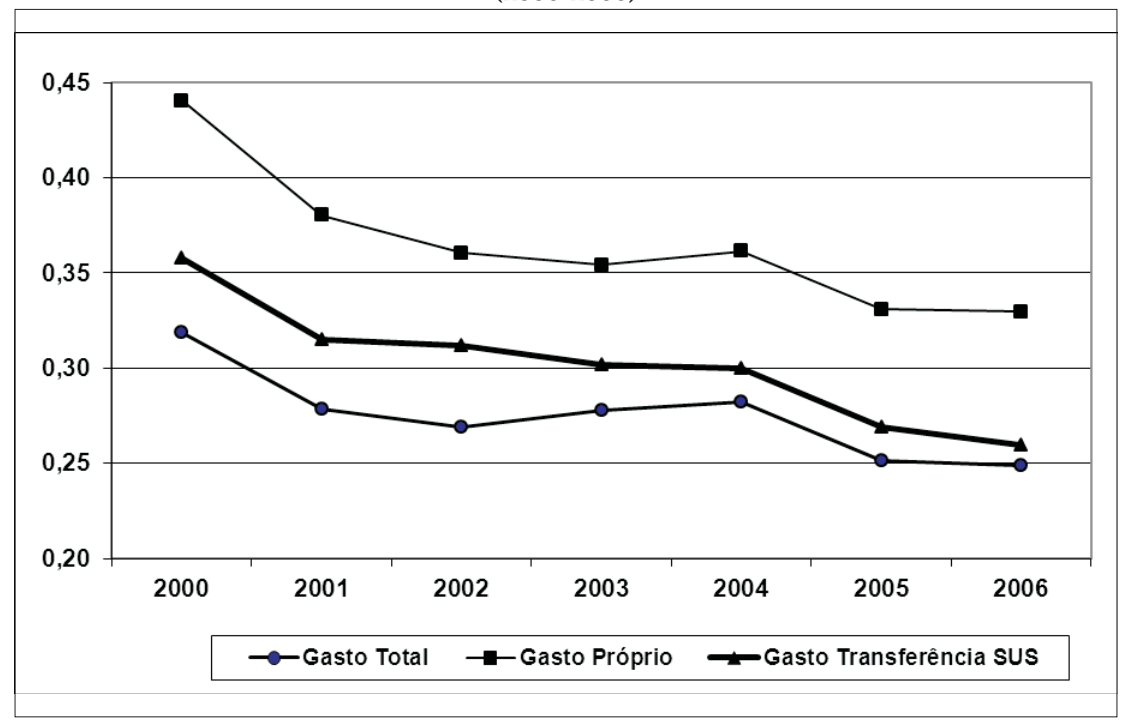

Fonte: SIOPS/DATASUS.

mo tempo, o percentual mínimo também pode ter servido como referência para os municípios como um todo, apesar da ausência de impedimentos aos governantes de destinar parcelas maiores dos seus orçamentos à saúde. Dessa forma, as desigualdades no gasto municipal em saúde passam a ser mais explicadas pelas diferenças na capacidade fiscal de cada município (quanto aos recursos disponíveis) do que pela decisão de gasto dos governantes, condicionada pela regulação federal.

Em relação às transferências do SUS, também foi possível notar uma acentuada queda da desigualdade na distribuição destes recursos entre os municípios brasileiros em função dos critérios redistributivos que norteiam estes repasses. De um lado, as transferências do PAB fixo são definidas através de um valor per capita, com uma pequena variação de acordo com as características dos municípios. Do outro, as transferências condicionadas do PAB variável dependem da adesão e da expansão da oferta municipal dos programas definidos como prioritários. Neste sentido, como a oferta como um todo se expandiu, as diferenças dos repasses diminuíram, explicando a queda do coeficiente 
de Gini em relação ao gasto em saúde financiado com recursos das transferências SUS.

Por último, deve-se ressaltar que a queda na desigualdade no gasto total em saúde foi maior que a redução das desigualdades observada nas fontes de recursos (próprios e SUS) separadamente, isto é, o coeficiente de Gini no gasto total (com as duas fontes agregadas) foi menor em todos os anos analisados, em comparação com os índices observados com as fontes de recursos desagregadas. Isto se deve ao fato de as duas fontes serem complementares: os municípios que recebem mais recursos das transferências do SUS são aqueles com menor capacidade de gasto próprio por habitante, ambas se complementam e colaboram para reduzir a desigualdade horizontal no gasto em saúde como um todo.

Em suma, conclui-se que:

1) A regulação federal na área da saúde resultou em aumento do gasto municipal em saúde com recursos próprios, em função dos efeitos da vinculação dos recursos destas esferas imposta pela EC 29. Já as transferências federais do SUS contribuíram menos com a expansão do gasto, pois apesar do aumento real observado, seria possível uma ampliação maior dos gastos federais, uma vez que não houve correção adequada dos valores de referência para os repasses.

2) Os resultados revelam que houve ampliação da cobertura da atenção básica, cujos procedimentos são executados localmente, mas com diretrizes definidas centralmente, estabelecendo, assim, um padrão nacional de atuação descentralizada da política.

3) A estratégia de regulação também foi capaz de reduzir as desigualdades horizontais no financiamento da saúde, pois estabeleceu um patamar mínimo de gasto próprio e condicionou repasses adicionais à ampliação da oferta municipal das ações e serviços de saúde.

\section{CONSIDERAÇÕES FINAIS}

Após a análise das alterações no desenho das políticas e do funcionamento dos mecanismos de regulação federal, é possível concluir que as reformas institucionais resultaram na ampliação do gasto e da oferta municipal das políticas de educação e saúde e na redução das desigualdades horizontais no financiamento destas políticas.

DADOS - Revista de Ciências Sociais, Rio de Janeiro, vol. 57, nº 4, 2014 
Para alcançar estes resultados, foi preciso obter a adesão dos governantes municipais para que eles assumissem a oferta das políticas, sob diretrizes definidas centralmente. Era necessário fornecer incentivos corretos que contemplassem os interesses dos entes subnacionais e que fossem adequados ao legado da política em questão, considerando a distribuição de competências original, as responsabilidades de cada esfera em relação ao financiamento e a existência de regras anteriores em vigor.

As descentralizações do ensino fundamental e da atenção básica de saúde, já previstas na Constituição de 1988, só foram efetivamente concretizadas após as reformas implementadas na segunda metade dos anos 1990. A partir de diferentes mecanismos jurídico-institucionais utilizados de acordo com as especificidades das políticas, as reformas promoveram mudanças nas regras de financiamento das políticas, visando condicionar os repasses à oferta dos programas definidos como prioritários, cujas diretrizes são definidas centralmente nas pastas ministeriais responsáveis por cada política setorial. A partir de então, os governos municipais puderam contar com uma fonte adicional e segura de recursos, que estaria disponível apenas se os governantes optassem por assumir a oferta dos programas selecionados e nos moldes definidos pelo governo federal, estabelecendo um processo de descentralização regulada e um padrão nacional de execução local das políticas reguladas.

Na política de educação, os resultados obtidos após a introdução do Fundef foram: o forte crescimento inicial das matrículas; a municipalização da oferta deste nível de ensino; a correção das desigualdades intraestaduais, já que o valor aluno/ano repassado por cada fundo estadual independe da capacidade contributiva de cada esfera de governo; e, por fim, as desigualdades horizontais no plano nacional (interestaduais) - em relação ao valor por aluno/ano disponível para o investimento em educação (receitas vinculadas à MDE) - seriam muito maiores caso o Fundef não vigorasse, apesar do limitado papel da União no financiamento do fundo, em função do baixo valor mínimo nacional definido.

Na política de saúde, a vinculação de receitas e a normatização das transferências federais condicionadas à oferta de ações de atenção básica e de programas específicos resultaram em um crescimento significativo na produção ambulatorial dos sistemas municipais de saúde e a 
expansão da oferta do PSF em todo o território nacional; no aumento do gasto total em saúde, puxado por uma expansão mais forte dos gastos próprios dos governos municipais; e, por último, houve uma forte diminuição das desigualdades horizontais no financiamento da saúde, em função da redução das diferenças no gasto próprio em saúde, como também em função de uma distribuição mais equânime das transferências do SUS.

Contudo, os recursos transferidos aos municípios - pelo Fundef ou via transferências do SUS - devem ser complementados por outros recursos provenientes do orçamento municipal, pois não cobrem integralmente os custos de oferta dos serviços. A aplicação dos recursos próprios municipais se tornou mais necessária à medida que os repasses federais - via complementação da União ao Fundef e dos valores transferidos pelo PAB (fixo e variável) - perderam importância relativa no financiamento das políticas de educação e saúde, uma vez que o valor mínimo aluno/ano do Fundef, o valor per capita do PAB fixo e os valores dos incentivos financeiros do PSF não foram reajustados adequadamente. Para garantir a complementação de recursos próprios municipais, foram instituídas (ou reafirmadas) vinculações das receitas disponíveis aos municípios para o financiamento das políticas de educação e saúde, nos dois casos através de Emendas Constitucionais.

(Recebido para publicação em novembro de 2012)

(Reapresentado em setembro de 2014)

(Aprovado para publicação em novembro de 2014) 


\section{Daniel Arias Vazquez}

\section{NOTAS}

1. Em ambos os casos, as regras foram renovadas por novas regulações. O Fundef foi substituído pelo Fundeb (Fundo de Manutenção e Desenvolvimento da Educação Básica), que ampliou a cobertura para os demais níveis de ensino da Educação Básica e montante de recursos vinculados ao novo fundo. Já o PAB foi renovado pelo Pacto pela Saúde -2006, editado pela Portaria no 399/2006, consolidando os repasses federais aos municípios que assumissem a gestão da atenção básica à saúde. Esta continuidade se deve ao caráter irreversível da regulamentação destas políticas, pois apesar do término previsto inicialmente, não seria possível simplesmente um retorno à situação anterior. A despeito disso, o escopo deste artigo trata das primeiras regulações (Fundef e PAB), cujos impactos no financiamento e na oferta destas políticas são maiores, o que permite testar a eficácia destes mecanismos frente aos objetivos propostos (ampliação do gasto, descentralização e redução das desigualdades). Será analisado todo o período de vigência destes programas (1998-2006), sendo que no caso da saúde, há ainda a vinculação de receitas dos governos subnacionais, pela EC no 29, introduzida dentro do período analisado (em 2000).

2. Inseridas em uma agenda política e em um debate teórico internacional sobre a Reforma do Estado, estas reformas institucionais, também conhecidas como de segunda geração, tinham como objetivo aperfeiçoar a ação do Estado e melhorar a eficácia e a eficiência das políticas sociais. No seu sentido mais amplo, esta agenda de reformas visava construir uma nova regulação estatal sobre o mercado, a partir da recuperação da capacidade regulatória do Estado, o que implica o fortalecimento das instituições, com a definição de regras e incentivos necessários para a cooperação entre os agentes econômicos no mercado e para uma gestão pública mais adequada à condução do desenvolvimento (Kuczynski e Williamson, 2003; Stiglitz, 1998). Esta definição acima pode ser facilmente adaptada para explicitar a importância das instituições para a coordenação federativa no Brasil, pois elas ditam regras e colocam incentivos que condicionam a decisão dos governantes locais em direção a um comportamento esperado, convergente às diretrizes da política econômica e da estratégia social, ambas definidas centralmente.

3. A complementação da União foi bastante residual, tendo em vista o baixo valor mínimo estipulado pelo governo federal a cada ano (Vazquez, 2007). Diante disso, a análise sobre a composição do fundo se concentrará nos recursos oriundos das receitas dos estados e municípios vinculadas ao Fundef. Esta participação da União será retomada quando forem analisados os efeitos dos fundos sobre as desigualdades horizontais.

4. Este valor é fictício, pois corresponde à média aritmética simples que considera no numerador apenas as receitas vinculadas a MDE pela Constituição (25\%), e não o valor efetivamente aplicado, já que não existe consolidação deste dado. No denominador, foram agregadas todas as matrículas municipais da rede pública municipal, independente da etapa e da modalidade de ensino da educação básica.

5. No banco de dados Edudata Brasil, do Inep, as matrículas estão disponíveis apenas a partir de 1999. Como os recursos são orientados pelo censo do ano anterior, só foi possível iniciar a análise no ano 2000. Outro fator importante que justifica a exclusão dos anos de 1998 e 1999 da análise é a dificuldade inicial dos municípios em classificar corretamente o saldo de recursos recebidos pelo Fundef no sistema de coleta de 
dados da base Finbra (STN). A partir do terceiro ano de vigência do fundo, tais erros são significativamente reduzidos e, consequentemente, não afetam a análise realizada neste estudo.

6. O período analisado neste artigo é, portanto, anterior à regulamentação da $\mathrm{EC}$ n을. 29 . De acordo com Marques e Mendes (2005:167), a ausência de regulamentação da EC 29 impediu o aumento de recursos para a saúde, especialmente por parte da União. Segundo cálculo dos autores, "a diferença entre o valor legal e o valor aplicado, com base na interpretação do Ministério da Fazenda, somou $R$ \$ 1,8 bilhão nos três primeiros anos (2001, 2002 e 2003)". Antes da regulamentação, Marques e Mendes (2005) alertaram também para possíveis irregularidades constantes na inclusão de despesas que não são da área de saúde para que o patamar mínimo de gasto fosse alcançado.

7. Diferentemente do financiamento da educação, cuja equalização se deu através da redistribuição dos recursos entre governo estadual e municipais dentro de cada UF (intraestadual), o financiamento da saúde prevê apenas o gasto com recursos próprios de cada esfera e com recursos transferidos fundo a fundo (transferências do SUS). Dessa forma, cada município terá um gasto per capita diferente do outro, pois não há mecanismos de equalização estadual, como é o caso da educação, quando o Fundef e Fundeb repassam um valor único por aluno/ano dentro de cada estado. Para trabalhar com as informações do gasto desagregadas por município, foi necessário retirar da análise o ano de 1999, pois para este exercício estão disponíveis apenas dados agregados por UF. Estas informações estão disponíveis em um sistema próprio de monitoramento dos recursos aplicados pelos municípios (SIOPS/ DATASUS), no site http://siops.datasus.gov.br/. 


\section{REFERÊNCIAS BIBLIOGRÁFICAS}

ABRUCIO, Fernando. (2005), “Coordenação Federativa no Brasil: A Experiência do Período FHC e os Desafios do Governo Lula". Revista de Sociologia e Política, vol. 24, pp. 41-67.

AFFONSO, Rui de Britto Álvares. (1995), “A Federação no Brasil: Impasses e Perspectivas", in R. B. Affonso e P. L. B. Silva (orgs.), A Federação em Perspectiva: Ensaios Selecionados. São Paulo, Fundap, pp. 57-76.

ALMEIDA, Maria Hermínia Tavares de. (2005), "Recentralizando a Federação?". Revista de Sociologia e Política, vol. 24, pp. 29-40.

ARRETCHE, Marta. (1999), “A Federação Brasileira: Crise ou Construção?”. Revista Teoria \& Debate, no 41 , pp. 21-26.

(2002), “Federalismo e Relações Intergovernamentais no Brasil: A Reforma de Programas Sociais". DADOS - Revista de Ciências Sociais, vol. 45, no 3, pp. 431-458.

(2004), "Federalismo e Políticas Sociais no Brasil: Problemas de Coordenação e Autonomia". São Paulo em Perspectiva, vol. 18, no 2, pp. 17-26.

(2009), “Continuidades e Descontinuidades da Federação Brasileira: De como 1988 Facilitou 1995". DADOS - Revista de Ciências Sociais, vol. 52, no 2, pp. 377-423.

CAJUEIRO, Juliana P. de Moura. (2004), Saúde Pública no Brasil nos Anos Noventa: Um Estudo da Política e de seus Limites e Condicionantes Macroeconômicos. Dissertação de Mestrado em Economia Social e do Trabalho, Instituto de Economia (IE/ Unicamp), Universidade Estadual de Campinas.

CASTRO, Jorge Abraão et al. (2009), "A CF/88 e as Políticas Sociais Brasileiras", in J. C. Cardoso Jr. (org.), A Constituição Brasileira de 1988 Revisitada: Recuperação Histórica e Desafios Atuais das Políticas Públicas nas Áreas Econômica e Social. Brasília, IPEA, vol. 1, pp. 55-122.

GOMES, Sandra. (2008), Fatores Explicativos das Diferentes Estratégias de Municipalização do Ensino Fundamental nos Governos Subnacionais do Brasil (1997-2000). Tese de Doutorado em Ciência Política, Faculdade de Filosofia, Letras e Ciências Humanas, Universidade de São Paulo, São Paulo.

(2009), “Políticas Nacionais e Implementação Subnacional: Uma Revisão da Descentralização Pós-Fundef". DADOS - Revista de Ciências Sociais, vol. 52, no 3, pp. 659-690.

KUCZYNSKI, Pedro Pablo e WILLIAMSON, John. (2003), Depois do Consenso de Washington: Retomando o Crescimento e a Reforma na América Latina. São Paulo, Editora Saraiva.

LOBO, Teresa. (1995), “Distribuição de Encargos na Área Social”, in R. B. A. Affonso e P. L. B. Silva (orgs.), A Federação em Perspectiva: Ensaios Selecionados. São Paulo, Fundap, pp. 305-314.

MARQUES, Rosa Maria e MENDES, Áquilas. (2005), “Os Dilemas do Financiamento do SUS no Interior da Seguridade Social". Economia e Sociedade, no 24, pp. 159-175.

MELAMED, Clarice e COSTA, Nilson do Rosário. (2003), "Inovações no Financiamento à Atenção Básica". Ciência e Saúde Coletiva, vol. 8, no 2, pp. 393-401. 
MELO, Marcus André. (2005), “O Sucesso Inesperado das Reformas de Segunda Geração: Federalismo, Reformas Constitucionais e Política Social". DADOS - Revista de Ciências Sociais, vol. 48, no 4, pp. 445-489.

MENDES, Marcos José. (2003), “A Eficácia da Vinculação de Recursos no Federalismo Brasileiro: O Caso do FUNDEF", in Secretaria do Tesouro Nacional, Finanças Públicas. Brasília, Editora da UnB, pp. 275-330.

OLIVEIRA, Fabrício A. de. (2003), “Fundef e Saúde: Duas Experiências (Virtuosas?) de Descentralização", in F. Rezende e F. A. Oliveira (orgs.), Descentralização e Federalismo Fiscal no Brasil: Desafios da Reforma Tributária. Rio de Janeiro, Konrad Adenauer Stiftung, pp. 203-272.

PRADO, Sergio. (2007), A Questão Fiscal na Federação Brasileira: Diagnósticos e Alternativas. Brasília, IPEA/CEPAL (Relatório de Pesquisa "Brasil: O Estado de uma Nação").

SERRA, José e AFONSO, José Roberto. (1999), “O Federalismo Fiscal à Brasileira: Algumas Reflexões". International Conference on Federalism, Textos. Disponível em http:/ / www.bndes.gov.br/SiteBNDES/export/sites/default/bndesãpt/Galerias/Arquivos/bfãbancos/e0001793.pdf. Acesso em 20/5/2012.

SOLLA, Jorge et al. (2007), "Mudanças Recentes no Financiamento Federal do Sistema Único de Saúde: Atenção Básica à Saúde". Revista Brasileira de Saúde Materno Infantil, vol. 7, no 4, pp. 495-502.

SOUZA, Renilson Rehem de. (2003), "Redução das Desigualdades Regionais na Alocação dos Recursos Federais para a Saúde". Ciência e Saúde Coletiva, vol. 8, no 2, pp. 449-460.

STIGLITZ, Joseph. (1998), "More Instruments and Broader Goals Moving toward the Post-Washington Consensus". The 1998 WIDER Annual Lecture, Helsinki. Disponível em http:/ / www.ucm.es/info/eid/pb/Stiglitz98wider.pdf. Acesso em 15/6/2012.

VAZQUEZ, Daniel Arias. (2003), “Educação e Desigualdades Regionais: Os Impactos Fiscais do FUNDEF", in Secretaria do Tesouro Nacional, Finanças Públicas. Brasília, Editora da UnB, pp. 433-494.

. (2007), “Desigualdades Interestaduais no Financiamento da Educação: O Caso do Fundef", in G. Hochman; M. Arretche e E. Marques (orgs.), Políticas Públicas no Brasil. Rio de Janeiro, Editora Fiocruz, pp. 245-274.

. (2012), Execução Local sob Regulação Federal: Impactos da LRF, Fundefe SUS nos Municípios Brasileiros. São Paulo, Annablume/Fapesp.

VIANA, Ana Luíza d'Ávila e MACHADO, Cristiani Vieira. (2009), “Descentralização e Coordenação Federativa: A Experiência Brasileira na Saúde”. Ciência e Saúde Coletiva, vol. 14, no 3, pp. 807-817.

VIANNA, Sollon. (2005), "A Seguridade Social e o SUS: Revisitando o Tema”. Revista Saúde e Sociedade, vol. 14, no 1, pp. 7-22. 


\section{RESUMO}

Mecanismos Institucionais de Regulação Federal e seus Resultados nas Politicas de Educação e Saúde

Este artigo analisa o arranjo federativo definido por reformas institucionais implantadas nos anos 1990, as quais definiram um modelo de execução local das políticas descentralizadas no Brasil, sob diretrizes definidas centralmente. Estas reformas levaram em conta as necessidades de expansão da oferta e de estímulo à descentralização, além de definir quais mecanismos de redistribuição dos recursos e de compatibilização entre receita e oferta seriam mais adequados para cada política. A partir da análise das políticas de educação e saúde, foi possível comprovar a eficácia da regulação federal em obter a adesão dos governos municipais, com: a) a ampliação da oferta municipal das matrículas de ensino fundamental e das ações de atenção básica de saúde; e b) o aumento dos gastos per capita aplicados nos municípios e redução da desigualdade horizontal no financiamento da educação (Fundef) e da saúde (Piso de Atenção Básica), medida pelo coeficiente de Gini, durante o período de vigência de cada mecanismo de regulação (1998 a 2006).

Palavras-chave: regulação federal; descentralização; educação; saúde; municípios brasileiros

\section{ABSTRACT \\ Institutional Mechanisms of Federal Regulation and its Results on Education and Health Policies}

This article analyzes the federative arrangements defined by institutional reforms implemented in the 1990s, which defined a model of local execution of decentralized policies in Brazil under centrally defined guidelines. These reforms took into account the needs of the expansion of supply and stimulus to decentralization, in addition to defining which mechanisms of redistribution of resources and compatibility between revenue and supply would be more adequate for each policy. Based on the analysis of health and education policies, it was possible to prove the efficiency of federal regulation in garnering the support of municipal governments with: a) the broadening of municipal enrollment in basic education and basic health assistance; and $b$ ) the increase of expenditures per capita in municipalities and the reduction of horizontal inequality in the financing of education (Fundef) and health (Lowe Threshold for Basic Care). The measurement was based on the Gini coefficient during the entire duration of each mechanism of regulation (1998 to 2006).

Keywords: federal regulation; decentralization; education; health; Brazilian municipalities 


\section{RÉSUMÉ}

Mécanismes Institutionnels de Réglementation Fédérale et ses Résultats sur les Politiques d'Education et de Santé

Cet article analyse le concert fédéral défini par les réformes institutionnelles mises en œuvre dans les années 1990, qui ont établi un modèle d'exécution locale des politiques décentralisées au Brésil, conformément aux lignes directrices indiquées centralement. Ces réformes ont pris en compte les besoins d'expansion de l'offre et de stimulation de la décentralisation, et ont défini quels mécanismes de redistribution des ressources et de comptabilisation entre recette et offre seraient les plus appropriés pour chaque politique. De l'analyse des politiques d'éducation et de santé, il a était possible de prouver l'efficacité de la réglementation fédérale pour obtenir l'adhésion des gouvernements municipaux, avec: a) l'expansion de l'offre municipale de scolarisation dans le primaire et des action d'attention basique de santé; b) l'augmentation des dépenses par habitant appliquées dans les villes et réduction des inégalités horizontales dans le financement de l'éducation (Fundef) et de la santé (Seuil d'Attention Basique). La mesure a été donnée par le coefficient de Gini, tout au long de la durée de chaque mécanisme de régulation (1998-2006).

Mots-clés: réglementation fédérale; décentralisation; éducation; santé; municipalités brésiliennes

\section{RESUMEN}

Mecanismos Institucionales de Regulación Federal y sus Resultados en las Politicas de Educación y Salud

Este artículo analiza el arreglo federativo definido por reformas institucionales implementadas en los años 1990, las cuales definieron un modelo de ejecución local de las políticas descentralizadas en Brasil bajo directrices definidas centralmente. Estas reformas llevaron en cuenta las necesidades de expansión de la oferta y de fomento a la descentralización, además de definir qué mecanismos de redistribución de recursos y de compatibilización entre ingresos y oferta serían más adecuados para cada política. A partir del análisis de las políticas de educación y salud, ha sido posible comprobar la eficacia de la regulación federal en obtener la adhesión de los gobiernos municipales en dos frentes: a) la ampliación de la oferta municipal de las matrículas de enseñanza primaria y de las acciones de atención básica en salud; b) el incremento de los gastos per capita aplicados en los municipios y la reducción de la desigualdad horizontal en la financiación de la educación (Fundef) y la salud (Piso de Atención Básica). La medición se hizo por el coeficiente Gini, durante el periodo de vigencia de cada mecanismo de regulación (1998 a 2006).

Palabras clave: regulación federal; descentralización; educación; salud; municipios brasileños 